\title{
Integrando tecnologia digital no contexto do ensino de Física e Química na preparação para o Enem
}

\author{
XAVIER, L. A ${ }^{1 *}$; SEGATTO, B. R. ${ }^{1}$; Rodrigues, C. F. ${ }^{2}$; SONDERMANN, D.V.C ${ }^{2}$; LEITE, \\ Sidnei Quezada Meireles ${ }^{2}$; XAVIER, M.G ${ }^{3}$. \\ 1 Programa de Pós-Graduação em Ensino de Física (PPGEnFis), Universidade Federal do Espírito Santo UFES, \\ Vitória, ES, Brasil. \\ 2 Programa de Pós-Graduação em Educação em Ciências e Matemática (EDUCIMAT), Instituto Federal do Espírito \\ Santo (IFES), Vitória, ES, Brasil. \\ 3 Escola Sesc de Ensino Médio, Jacarepaguá, RJ, Brasil.
}

*e-mail: lucas.perobas@gmail.com

\begin{abstract}
Resumo
Nos últimos anos têm se discutido sobre metodologias ativas com propósito de melhorar a aprendizagem de nossos educandos. A fim de inovar, foi introduzido o ensino híbrido, como prática pedagógica para fortalecer a capacidade das escolas Prof. ${ }^{a}$ Filomena Quitiba e Coronel Gomes de Oliveira de impactar mais diretamente nos resultados de seus alunos do Ensino Médio no Exame Nacional do Ensino Médio (Enem). Proporcionando aos alunos condições de serem protagonistas na construção de seu conhecimento de Física e Química a partir da sua própria ação, explorando a construção de mapas mentais até às competências e habilidades exigidas pelo Enem, por meio da produção de podcast. A realização de transmissão de arquivos multimídia, como recurso mediador foi com o objetivo de obter melhor aprendizagem, criando a cultura de autoria com os estudantes para alavancar a qualidade do ensino. Foram realizadas oficinas nas turmas a fim de orientar para a produção dos podcasts das questões do Enem. Os recursos mais utilizados no processo foram: Computadores, data show; aplicativo Hora do Enem, softwares, livros, celular dos alunos. Portanto, o ensino híbrido que alternou momentos de aprendizagem individual e/ou coletivo sem abandonar as aulas expositivas teve o objetivo alcançado mostrando como o ensino híbrido pode ser um trabalho mediado pela cultura digital.
\end{abstract}

Palavras chave: Ensino Híbrido, Enem, TICs.

\begin{abstract}
In recent years it has been discussed about active methodologies for purposes of improving the learning of our students. In order to innovate, was introduced the hybrid teaching as a pedagogical practice to strengthen the ability of schools Prof. ${ }^{a}$ Filomena Quitiba and Coronel Gomes de Oliveira to have a more direct impact on the results of their high school students at High School National Exam (Enem). Providing students with the ability to be protagonists in building their knowledge of Physics and Chemistry from their own action, exploring the construction of mental maps to the skills and abilities required by Enem, through the production of podcast. The accomplishment of multimedia files transmission, as mediator resource was with the objective of obtaining better learning, creating the culture of authorship with the students to leverage the quality of the teaching. Workshops were held in groups to guide the production of the podcasts about Enem issues. The most used resources in the process were: Computers, data show; Enem Time application, software, books, student's cell phone. Therefore, hybrid teaching that alternated moments of individual and / or collective learning without abandoning the lectures had the objective reached showing how hybrid teaching can be a work mediated by digital culture.
\end{abstract}

Keywords: Hybrid Teaching, Enem, ICT 


\section{Introdução}

Atualmente a disponibilidade de ferramentas tecnológicas no ciberespaço, definido por Lévy [1] "como o espaço de comunicação aberto pela interconexão mundial dos computadores e das memórias dos computadores" abre caminhos para uma educação inovadora. Segundo Moran (2004) [2], a escola pode ser um espaço de inovação, de experimentação saudável de novos caminhos. Não precisamos romper com tudo, mas implementar mudanças e supervisioná-las com equilíbrio e maturidade. Segundo o autor, as tecnologias são só apoios, meios. Mas elas nos permitem realizar atividades de aprendizagem de formas diferentes às de antes. E é nessa perspectiva de inovação que se apresenta a proposta de integrar a tecnologia digital no ensino de Física e de Química, por meio da utilização do recurso podcast na preparação para o Enem e outros exames, como estratégia didática. De acordo com Bottentuit Junior [3]:

O podcast é um arquivo em áudio (em alguns casos, também pode combinar o uso de vídeo) que pode ser gravado tanto pelo professor como pelo aluno, possui pequenas dimensões e as temáticas são variadas, desde um conceito até mesmo um feedback sobre um trabalho realizado.

E segundo Pisa (2012, p. 72) apud Bottentuit Junior [3]: "o podcast é uma evolução tecnológica que pode servir para alavancar e apoiar as antigas e/ou tradicionais formas de educação, mas também, a ela, está reservada a possibilidade de transformação da aprendizagem".

A partir de 2009, o Enem passou por uma reformulação, com novas exigências para o acesso e o ingresso nas universidades públicas pelo Sistema de Seleção Unificada (SISU). A Universidade Federal do Espírito Santo (UFES) adotou o Enem em 2000 com $25 \%$ da nota da primeira fase e a partir de 2010 foi adotado o resultado dos candidatos como critério da primeira fase. E, em 2017, a UFES, aderiu ao SISU, assim como as demais instituições federais. A mudança da prática pedagógica devido ao baixo desempenho dos alunos no Enem foi necessária para deixá-los em melhores condições para este tipo de avaliação.

O desempenho dos alunos no Enem disponível na Tabela 1, na Área de Ciência da Natureza das duas escolas, é abaixo de 50\%, representando nosso maior problema.

\begin{tabular}{cccc} 
Tabela 1: QEdu.org.br. Microdados do Enem/Inep & \\
\hline Enem & $\begin{array}{c}\text { Ciências da } \\
\text { Natureza }\end{array}$ & $\begin{array}{c}\text { EEEFM } \\
\text { Filomena } \\
\text { Quitiba }\end{array}$ & $\begin{array}{c}\text { EEEFM Cel } \\
\text { Gomes de } \\
\text { Oliveira }\end{array}$ \\
\hline 2009 & 1000 pontos & 500 & 482 \\
\hline 2010 & 1000 pontos & 483 & 475 \\
\hline 2011 & 1000 pontos & 466 & 457 \\
\hline 2012 & 1000 pontos & 461 & 466 \\
\hline 2013 & 1000 pontos & 455 & 481 \\
\hline 2014 & 1000 pontos & 470 & 491 \\
\hline 2015 & 1000 pontos & 455 & 475 \\
\hline
\end{tabular}

Fonte: Adaptação dos autores

Por outro lado, a Secretaria de Educação (SEDU), com - Programa Sedu Digit@I disponibiliza ferramentas para alavancar o aprendizado dos alunos, sua motivação, engajamento e maior participação no processo da própria aprendizagem. A disponibilidade de conteúdo e de ferramentas digitais oportuniza o desenvolvimento da experiência digital integrada ao desenvolvimento e fortalecimento da aprendizagem. $\mathrm{O}$ programa também oferece ao professor recursos pedagógicos digitais e sugestões metodológicas, visando aprimorar a sua prática pedagógica e tornar as aulas mais dinâmicas, diversificadas e contextualizadas.

Na perspectiva de inovação foi realizada a integração da tecnologia digital no Ensino da Física e da Química, pela da utilização do recurso podcast na preparação para o Enem, desenvolvida trimestralmente com alunos das turmas de $1^{\circ}, 2^{\circ}$ e $3^{\circ}$ anos do Ensino Médio Regular das escolas da rede estadual Prof. ${ }^{a}$ Filomena Quítiba e Coronel Gomes de Oliveira localizadas, respectivamente, nos municípios de Piúma e Anchieta.

A utilização do podcast com os alunos, realizando transmissão de arquivos multimídia, como recurso 
mediador, objetiva obter melhor aprendizagem criando a cultura de autoria com os estudantes de todas as séries do ensino médio para potencializar a qualidade do ensino. Entretanto, a iniciativa de preparar os alunos para o Enem com a metodologia do ensino híbrido ajuda na reorganização do tempo e do espaço da aula.

Diante dessa realidade, como criar e manter a motivação dos alunos no ensino das disciplinas de Física e Química? Boruchovitch [4], diz que "há um conjunto de estímulos muito grande competindo com a sala de aula. Isto exige maior criatividade do professor, que deve propor situações que não se limitem ao decoreba e explorem a energia e a criatividade deles". Sobre a motivação ela pontua que há várias maneiras de motivá-los, o professor seria uma delas, que se coloque como modelo de pessoa que gosta do que faz. Uma alternativa é quando solicita trabalhos com possibilidades de feedbacks. "O feedback deve ser corretivo e informativo, apontando o problema detectado, mas também contendo orientações claras sobre como fazer para o aluno alcançar a meta".

Portanto, como levar os estudantes a serem protagonistas na construção do conhecimento a fim de melhorar o desempenho na avaliação do Enem? Como inovar nossa prática em sala de aula? São questionamentos frequentes em nosso percurso pedagógico. O tempo de aula é curto para que o professor coloque elementos que possam seduzir o aluno ao aprendizado. Dessa forma, quando o educando produz um podcast ele insere imagens, animações, elementos do seu interesse visual que levam às assimilações importantes na construção de sua aprendizagem. A proposta do trabalho almeja estimular o educando do Ensino Médio de duas escolas da rede estadual a se preparar para o Enem, nas disciplinas de Física e Química, utilizando a metodologia de ensino hibrido, como o podcast estimulando 0 protagonismo na produção de conhecimento.

\section{Materiais e métodos}

A metodologia adotada nessa prática baseia-se numa pesquisa de cunho qualitativo com estudo de caso através da produção e coleta de dados Lüdke e André [5]. Entretanto, o projeto foi organizado para a aplicação em três etapas que correspondem às séries do Ensino Médio Regular e os dados apresentados neste trabalho correspondem à primeira etapa.

Inicialmente realizamos uma avaliação diagnóstica dialógica para checar os conhecimentos prévios dos alunos objetivando auxiliar aluno e professor no processo ensino-aprendizagem no decorrer do processo. Segundo Belmont [6] o professor, ao organizar 0 ensino com foco na aprendizagem significativa, deve considerar os conhecimentos prévios dos alunos, estabelecer o conteúdo a ser ensinado/aprendido assim como organizá-lo de forma lógica e sequencial para favorecer as relações conceituais por parte dos alunos. As ideias trocadas nas turmas foram sobre Física e Química trabalhadas na escola e como os conteúdos destas disciplinas são cobrados na prova do Enem, e como são exigidas as competências e as habilidades. Constatamos que nossos alunos já possuem o hábito de usar dispositivos móveis, então há necessidade de maior familiarização com os elementos constituinte do computador para gerar potencialidades educacionais.

\section{1 Produção dos podcasts}

Foram selecionadas 47 questões do Enem pelos professores, abrangendo conteúdos de Física e de Química trabalhados anteriormente em sala de aula, conforme apresenta a Figura 1.

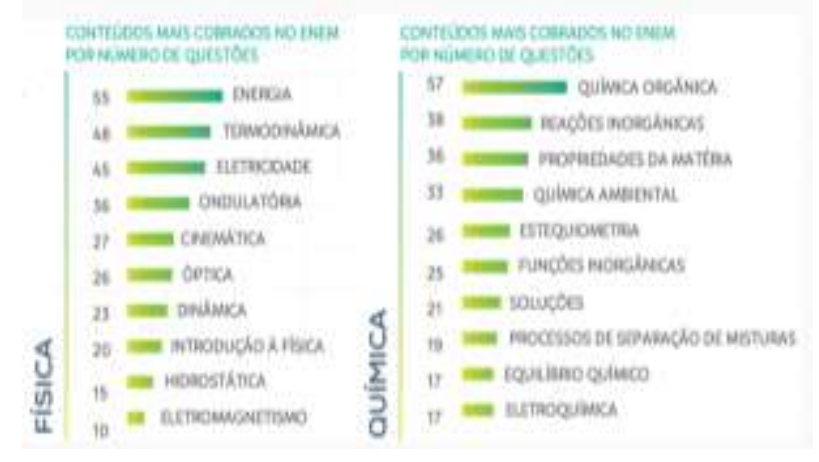

Figura 1: Conteúdos mais recorrentes na prova do Enem nas disciplinas de Física e Química (appprova.com.br)

De posse das questões os alunos participaram de oficinas para produção do podcast, utilizando os 
recursos: computadores, tablets, notebooks, data show; acesso à internet, aplicativo Hora do Enem, softwares: Word, Power Point, livros de física, dispositivos móveis dos alunos, revistas com questões do Enem, Programa Sedu Digit@I, site www.wikifisica.com, folhas A4, textos informativos, microfone, máquina de xerox, conforme Figura 2.

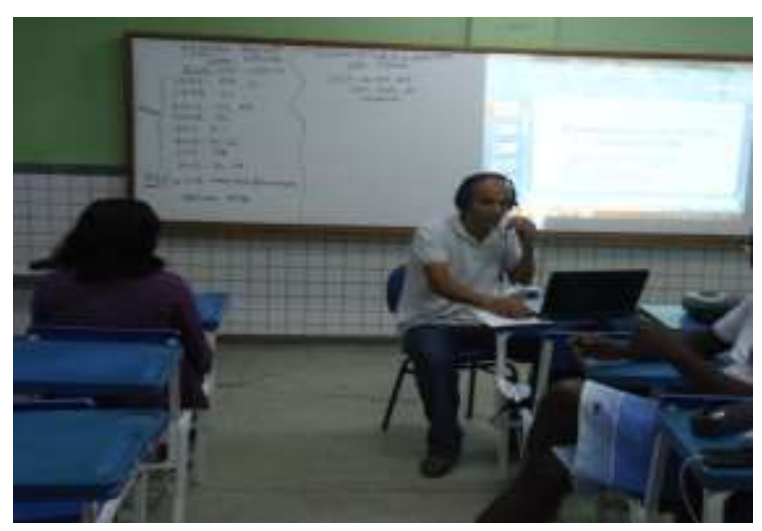

Figura 2: Início do trabalho com oficinas realizadas nas turmas.

Após a realização das oficinas os alunos se sentiram habilitados a produzirem seu podcast contendo: conceitos contemplados na questão do ENEM, competências e habilidades exploradas pela questão, mapa mental do percurso adotado pelo aluno, a questão selecionada e a discussão da mesma. Foram produzidos mais de 600 podcasts. Ao finalizarem os trabalhos, os alunos foram solicitados a responderem a um questionário como parte da avaliação do projeto e coleta de sugestões para o aperfeiçoamento da atividade em anos posteriores.

\section{Resultados e Discussões}

O projeto partiu da ideia de que é possível desenvolver uma atividade englobadora para o processo de aprendizagem dos alunos. Por meio do recurso podcast diversas habilidades foram desenvolvidas, ampliando a capacidade de utilização de diversas formas de linguagens expressas nesse tipo de apresentação. Os podcasts passaram por critérios de avaliação quanto à qualidade do áudio, conteúdo das disciplinas, seleção da competência do Enem e respectivas habilidades envolvidas na questão escolhida; o mapa mental elaborado, demonstrando os percursos realizados e a resposta à questão. Neste último o próprio aluno foi capaz de avaliar sua produção.

Como limitações para execução da atividade foram identificados erros do tipo: dificuldade em selecionar as competências e habilidades que correspondiam à questão e conceitos da física e da química. Sugerimos aos alunos a reestruturação da atividade com as correções necessárias. Na escola Professora Filomena Quitiba seis alunos questionaram: 'professor vai ter esta atividade chata no próximo trimestre?' Foi respondido: 'sim, pois a atividade vem sanar grande deficiência da escola em melhor preparação dos alunos para o Enem, é melhor errar agora e acertar no momento da avaliação'. Os feedbacks foram constantes e de acordo com a necessidade no atendimento dos grupos à proposta da atividade. Foram feitos elogios aos alunos pelo esforço dispendido na atividade e ao capricho e qualidade, fomentando assim, a motivação. Ao receber os trabalhos propomos novos desafios para os alunos no sentido de melhorar a qualidade: 'que tal adicionar Gifs, mapas mentais?' Após o desafio vimos que os podcasts ficaram mais dinâmicos e os alunos motivados. Com a intenção de analisar o impacto que o podcast trouxe e o que poderia ser feito no ano seguinte em busca de aperfeiçoamento do recurso, foi aplicado um questionário com quatro perguntas e para uma delas foi fornecida, pelos alunos, as seguintes respostas: cobrar dos alunos maior aprofundamento nos conteúdos de Física; podcasts mais breves e mais objetivos; mais computadores na escola; mais tira dúvidas; criação de aplicativo para o podcast; mais imagens explicativas; melhor qualidade do áudio; está bom do jeito que está; podcast em formato de vídeoaula; podcast feito em duplas; adoção do podcast pelos demais professores da escola; colocar mais animação no podcats com Gifs; aluno poder avaliar o podcast do outro; seria bem legal se usássemos a lousa digital; incluir diagrama Vê e vídeos no podcast; trabalhar com podcats o ano inteiro; a escola adotar o podcast como ferramenta de estudo; os melhores podcasts deveriam ser publicados no Youtube. 
A produção obtida nas disciplinas de Física (www.wikifisica.com/híbrido/) e na disciplina de Química, (www.wikifisica.com/podcasts-química/) totalizaram mais de 600 trabalhos. A ferramenta adotada no projeto foi aceita pelos estudantes do ensino médio que solicitaram a continuidade no ano seguinte. Em conformidade com Bottentuit Junior [3]:

De uma maneira mais ativa onde os professores selecionam conteúdos disponibilizam para os alunos estudarem e pedem aos mesmos que gravem podcasts como resultado da aprendizagem, desta forma eles terão que ler, resumir, esquematizar seu conteúdo e gravar, além do mais, através dos arquivos gravados eles podem contribuir com a formação dos seus colegas de classe.

Portanto, foi possível com a metodologia desenvolvida, dentro da perspectiva de ensino híbrido, abarcar uma gama de recursos voltados para aprendizagem, dentre eles a utilização de recursos de mídia digital. A prática possibilitou ainda o engajamento dos alunos nas diversas atividades de forma a contribuir com o protagonismo por meio de um planejamento personalizado e acompanhamento individual, apontando para uma nova forma de aprender, onde foram estimuladas a autonomia e a autoria de cada estudante.

\section{Conclusão}

No cenário contemporâneo, onde o uso de tecnologias é constante e diversificado, a metodologia do ensino híbrido utilizando como ferramenta o podcast se apresentou como um recurso metodológico de grande potencial educador. Foi possível desenvolver diversas habilidades dos estudantes no preparo para o Enem. Essas habilidades foram comprovadas a partir das produções realizadas e comunicadas pelos alunos. Com a crescente competitividade para ingresso nos cursos superiores, onde a porta de entrada é o Enem, é necessário que o aluno dedique mais tempo aos estudos. Com a proposta desenvolvida os alunos tiveram acesso ao tipo de avaliação proposta pelo exame nacional, explorando as habilidades e competências necessárias e identificando os conteúdos relacionados às questões. Com tudo isso, o tempo dedicado ao estudo desses conteúdos foi ampliado significativamente, uma vez que estavam no cerne do trabalho. Com o estímulo ao estudo preparatório para a avaliação Enem um grupo de alunos se organizou espontaneamente para estudos no contra turno, procurando alguns professores durante os planejamentos para esclarecimentos relacionados a alguns conteúdos. Além de melhorar o desempenho nas avaliações internas, nas duas escolas, o método influenciou a cultura dos estudantes e de outros professores em relação ao Enem, que passaram a organizar atividades como simulados, seleção e apresentação de reportagens atuais, inserção de charges em apresentações de seminários e confecção de murais com dicas, gráficos, tabelas, informações gerias relacionadas ao Exame, como mostra as figuras 3 e 4. Ou seja, despertou um olhar para as diversas formas de linguagens avaliadas pelo exame e que deveriam ser inseridas no cotidiano escolar.

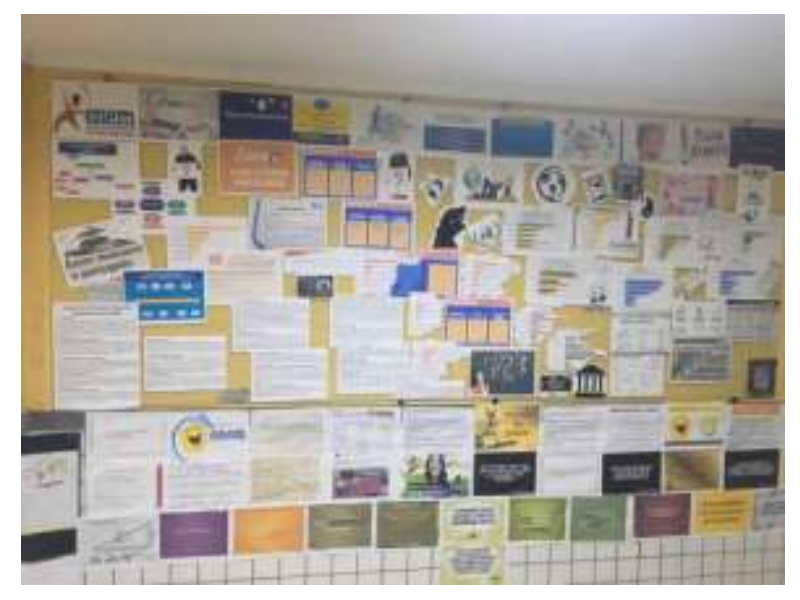

Figura 3: Mural confeccionado pelos alunos. 


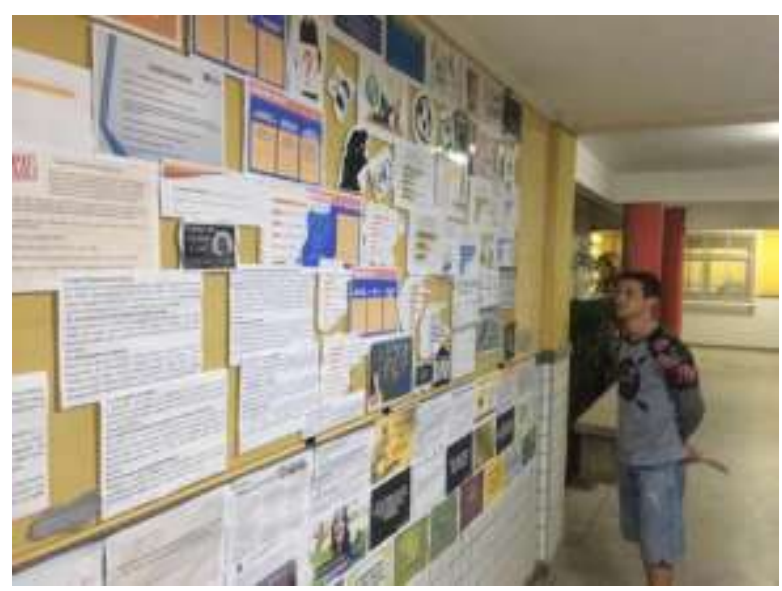

Figura 4: Exposição de mural.

Vale ressaltar que boa parte dos alunos, motivados pelo bom desempenho na metodologia adotada, se inscreveram para participação nos aulões oferecidos pela Secretaria de Educação do Estado. Entretanto, não podemos mensurar totalmente os resultados da prática adotada, uma vez que, estes dependem de avaliações do Enem e somente serão apurados após a realização dos mesmos, levando em conta que o projeto ainda se encontra em andamento.

\section{Agradecimentos}

Lucas Antônio Xavier agradece a CAPES pelo apoio financeiro devido à bolsa de mestrado. $E$, também ao doutorando Jefferson Oliveira do Nascimento as críticas construtivas e sugestões feitas ao trabalho apresentado no IX Encontro Científico de Física Aplicada - UFES, que foram postas em prática dentro do projeto em andamento.

\section{Referências}

[1] LÉVY, P. Cibercultura / Pierre Lévy: tradução de Carlos Irineu da Costa.- São Paulo: Ed. 34, 1999. 85 110

[2] MORAN, J. M. Contrapontos, v. 4, n. 2, p. 347-356, Itajaí, maio/ago. 2004.

[3] BOTTENTUIT JUNIOR, J. B. Revista EDUCAONLINE- Volume 7 - No 3 Setembro/Dezembro de 2013.

[4]. Mapeando a motivação dos alunos. Campinas. Disponível em $<$ http://www.unicamp.br/unicamp/unicamp hoje/ju/julho 2009/ju435pdf/Pag09.pdf>. Acesso em: Abril, 2018.

[5] LÜDKE, Menga e ANDRÉ, Marli E. D. A. Pesquisa em educação: abordagens qualitativas. São Paulo: EPU, 1986.

[6] Belmont, R. S. Revista/Meaningful Learning Review - V6(3), pp. 79-88, 2016. 